\title{
Design Enhancement of Forced Circulation Solar Water Heater for Residential Buildings in Saudi Arabia
}

\author{
Abdulmajeed A. Alshaye \\ Engineering Consultant, Saudi Aramco Oil Company, \\ P.O. Box 20463, Dhahran 31311, Saudi Arabia
}

\begin{abstract}
:
This study presents a proposed configuration of an innovative residential Solar Water Heater (SWH) system that will meet the hot water requirement and achieve a lower payback period in Saudi Arabia. Different SWH configurations were evaluated in terms of collector type, circulation method, heat exchanging mechanism and hot water storage. Also; the effect of SWH variable parameters on its thermal performance were determined. The variable parameters included collector tilt and orientation angles, albedo ratio, circulation flow rate, tank size, heat exchanger effectiveness and customer hot water supply temperature. The study covered five different cities, which represent different climate conditions. Proper optimization of SWH system configuration resulted in 30\% reduction in the system payback period, which is about 4.3 years. Better economic figures can be expected for the installation of SWH systems in commercial and industrial sectors.
\end{abstract}

Keywords: Solar water heating, System Advisor Model, SAM, Saudi Arab

DOI: $10.7176 / \mathrm{JETP} / 11-4-02$

Publication date:July $31^{\text {st }} 2021$

\section{Introduction:}

Increasing environmental concerns about global warming along with the fear of accelerated depletion of the fossil fuel resources have expedited the applications of renewable energy all over the world. This has also been supported by the rapid reduction in the cost of renewable energy technologies that made them more economical for residential, commercial, and industrial applications. Among all renewable energy systems, SWH systems have gained a widespread usage in residential buildings. According to Renewables 2019 Global Status Report [1] solar water heating and cooling have been implemented in more than 130 countries. By the end of 2018, the installed global capacity of solar thermal for water heating has reached $480 \mathrm{GW}$. In 2018 alone, $33.3 \mathrm{GW}$ of solar thermal capacity has been added, which presents a 7\% annual capacity increase. SWH systems are not environmentally friendly only, but also require lower operation and maintenance costs compared to other water heating technologies. SWH systems are economical with a payback period between two to four years depending on the type of application and location [2]. In Saudi Arabia, apart from few residential solar water heating projects, the majority of hot water requirement is being fulfilled using electricity or fossil fuel. The primary reason for low utilization of solar thermal energy in Saudi Arabia can be linked to the low conventional energy prices, which has recently changed due to the implementation of the government energy price reform program in 2017. Residential sector consumes about $44.8 \%$ of the total electricity generated in KSA [3]. A reduction in residential electricity consumption has been observed in the last few years, which is attributed to change in customers' behaviour due to the increase in electricity tariff. SWH for residential applications is a proven technology that has been widely implemented in many countries for over five decades. In countries like Barbados, Cyprus and Turkey, about $85 \%$ of residential houses have solar water heating systems on their roofs. Globally only $1.2 \%$ of water and space heating requirement in buildings is met by SWH systems. The heat demand of residential buildings accounts to $60 \%-85 \%$ of the total energy demand for houses located in cold climates, $30 \%-40 \%$ for buildings located in mild climates and 10\%-20 for buildings located in hot climates [4]. There is a large number of studies performed on solar water heating. Each study is usually focusing on a specific aspect of the solar water heating system, such as thermal performance, applications, economics, and configuration. Zell et al. 2015 [5] reports the results of first year solar data from measurements of 30 newly installed monitoring stations by King Abdullah City for Atomic and Renewable Energy (KACARE) in different locations in Saudi Arabia. The results indicated that the average daily global horizontal irradiance (GHI) was about $5,700 \mathrm{Wh} / \mathrm{m}^{2}$ with higher values for inland stations and lower values for stations along the coasts. The highest value of GHI was $7,300 \mathrm{Wh} / \mathrm{m}^{2}$ in the northwest part of Saudi Arabia, while the lowest one was 4,400 $\mathrm{Wh} / \mathrm{m}^{2}$. Figure 1 shows GHI map for Saudi Arabia [6]. 


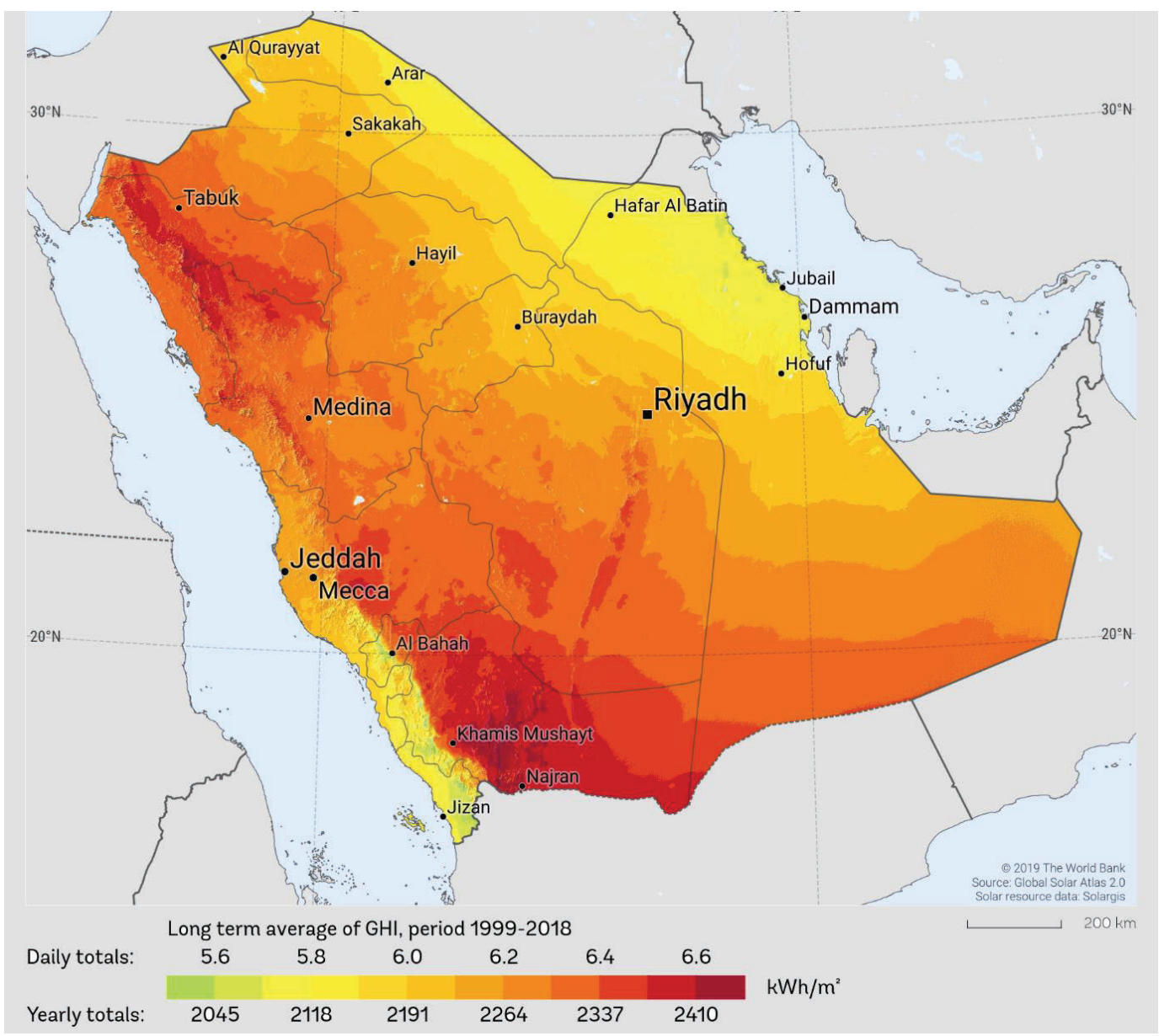

Figure 1: Saudi Arabia solar radiation map (2019) [6]

Hamad Almahmoud, 2015 [7] reported the results from an economical evaluation study on SWH applications in hospitals with a size of 200 beds or more in Saudi Arabia. The economic analysis shows the advantage of using glazed flat plate collector over evacuated tubes as these have shorter payback periods and higher annual life cycle savings. V.Santos [8] investigated the integration between the thermo-syphon SWH and the building environment in San Paulo, Brazil using Energy Plus modelling software. One of their major findings was that collector orientation is the main factor causing construction limitation. Thomas Kitzberger [9] studied the losses in the centralized forced SWH for a commercial building. Due to its long piping, the system will run at low efficiency $(2-12 \%)$ when the utilization rate is low. A careful measure needs to be established to maintenance high SWH system efficiency when dealing with centralized systems. Piotr Felinski and Jie Deng [10], [11] studied separately the benefits of using Phase Changing Material (PCM) on SWH performance. It was observed that there is a remarkable improvement in solar fraction when using PCM. PCM stability and aging is still an area of concern. Wen Tai [12] evaluated the SWH performance utilizing internet of things concepts. The case study was for a hospital in Singapore. The study identified the main three nonoptimal operation parameters and provided some recommendations to improve the SWH performance. Thalita Giglio [13] presented a study on the savings from subsidizing SWH for low income families in Brazil. The measured saving was between 9.5 $18.5 \mathrm{kWh}$ per person. The study indicated one of the major behaviour issues affecting the SWH performance related to mixing hot and cold water. Fahad A. Al-Sulaiman [14] evaluated different solar water heater technologies to establish a criterion for the optimum selection of collector type based on techno-economic aspects of each collector type. The study covered ten cities in Saudi Arabia with different climate zones. Results revealed that flat plate is the most economical collector type for most locations. Shahjadi Farjana [15] presented a global overview of solar energy applications to heat industrial processes. The majority potential industrial opportunities were explored with their targeted temperature ranges. A criterion for selecting the proper collector type was established based on economic and temperature limitations. Alemnew Endale [16] simulated using System Advisory Model software "SAM" for the economics and potential implementation of SWH in Ethiopia. The estimated potential saving was 1,480 GWh. The government effort to incentivise the deployment of SWH was explained aiming to minimize the heavy dependency on biomass energy source and minimize forest 
destruction. Tadahmun Yassen [17] et al. made an experimental work to investigate how the corrugated absorber can improve the efficiency of the integrated SWH design. They showed a large thermal loss for the system during night as a result easy path for heat escape from the integrated storage. Their works revealed that corrugated absorber design works better for integrated storage type than other designs. Elumalai Vengadesan [18] performed a comprehensive review on all the recent developments to improve the performance of a flat plate collector. Improving the heat transfer between the absorber plate and the heat transfer fluid, and the use of corrugated absorbers were among the most intensive research area.Salgado Conrdo [19] and Tania Urmee [20] addressed separately the problems and obstacles facing SWH in Mexico and Australia respectively. Common issues preventing widespread of SWH include low energy prices, high SWH capital cost and lack of SWH installation and operation knowledge.

The major takeaways from the literature review can be summarized as follows:

1. During the last 30 years the vast majority of research globally on SWH was done on residential and commercial applications with very limited research performed on industrial applications.

2. The SWH was found economical in most locations around the world including countries with low solar radiations.

3. There was a significant technological improvement over the last 30 years in the SWH, which have overcome the early designs problems.

4. There is no single SWH design suitable to all projects. Each application is to be treated individually considering location, size, water quality, plumbing system, capital cost, local know-how, etc.

5. Governmental regulations were found successful in some countries to expedite the implementation rate of SWH in residential sectors.

Some aspects of SWH that need more investigation include:

- Evaluation of different SWH systems and components to identify the most suitable design that meet residential sector requirement for selected climatic regions.

- Simulation and optimization of SWH system variable parameters to increase the overall system performance.

- $\quad$ Economic studies to benchmark the selected design of SWH against existing electrical water heater systems taking into consideration the recent implemented energy price reform in Saudi Arabia.

\section{Metrological data}

A reliable solar radiation data is paramount important for any research in the field of solar energy. Ground measured weather station data are normally more accurate and reliable than satellite weather data sources. A ground measured weather data provided by King Abdullah City for Atomic and Renewable Energy (KACARE) is used in this study. KACARE is sponsoring a program titled Renewable Resource Monitoring and Mapping (RRMM) for measuring weather data across 42 selected locations in Saudi Arabia [21]. The measured data includes the three main components of solar radiation, which are Direct Normal Irradiance (DNI), Global Horizontal Irradiance (GHI) and Diffuse Horizontal Irradiance (DHI). The DNI is of great importance for Concentrating Solar Power (CSP), while GHI is useful to calculate incident radiation on a tilted surface such as a solar thermal collector or a photovoltaic panel. The diffuse radiation has a significant influence for daylight building design. Table 1 summarize the ground station weather and geographical date for the five selected cities.

Table 1: Climatic data for the five selected cities [21]

\begin{tabular}{cccccc}
\hline Parameter & Riyadh & Dhahran & Tabuk & Taif & Abha \\
\hline Latitude & 24.53 & 26.3 & 28.38 & 21.43 & 18.22 \\
Longitude & 46.43 & 50.14 & 36.48 & 40.49 & 42.55 \\
Elevation (meter) & 895 & 75 & 781 & 1518 & 2173 \\
Global horizontal $(\mathrm{kW}-\mathrm{hr} /$ day) & 6.4 & 5.58 & 6.32 & 6.39 & 6.06 \\
Direct Beam $(\mathrm{kW}-\mathrm{hr} /$ day) & 6.17 & 5.34 & 7.41 & 6.15 & 5.96 \\
Diffuse horizontal $(\mathrm{kW}-\mathrm{hr} /$ day) & 2.24 & 2.03 & 1.57 & 2.23 & 2.02 \\
Average temperature $\left({ }^{\circ} \mathrm{C}\right)$ & 26.5 & 27.9 & 23 & 24.1 & 18.7 \\
Average wind speed $(\mathrm{m} / \mathrm{s})$ & 5.9 & 4.2 & 3.7 & 4.3 & 3.2 \\
& & & & &
\end{tabular}

\section{Solar Water Heaters (SWH)}

A SWH system can be classified according to their design into four categories, which are collector type, circulation method, system configuration and heat exchanging mechanism. Figure 2 shows different system arrangement of common SWH in use. As a result, SWH can be built with about 16 different designs. 




Figure 2: SWH different system design and arrangement

\section{SWH perspective in Saudi Arabia}

The implementation of SWH in Saudi Arabia is lagging the world fast growth of SWHs deployment. Apart from low energy prices, many of the early pilot SWH installations in the country did not meet the customer expectations and consequently provided SWH with a poor reputation. A careful evaluation of the previously installed SWH systems revealed that the problems are not related to the SWH technology itself, but rather due to bad design and installation practices. Figure 3 shows the world distribution of the $480 \mathrm{GW}$ installed capacity of SWH by the end of 2018. Since 1980; it is mandatory in some countries to install SWHs in new residential buildings.

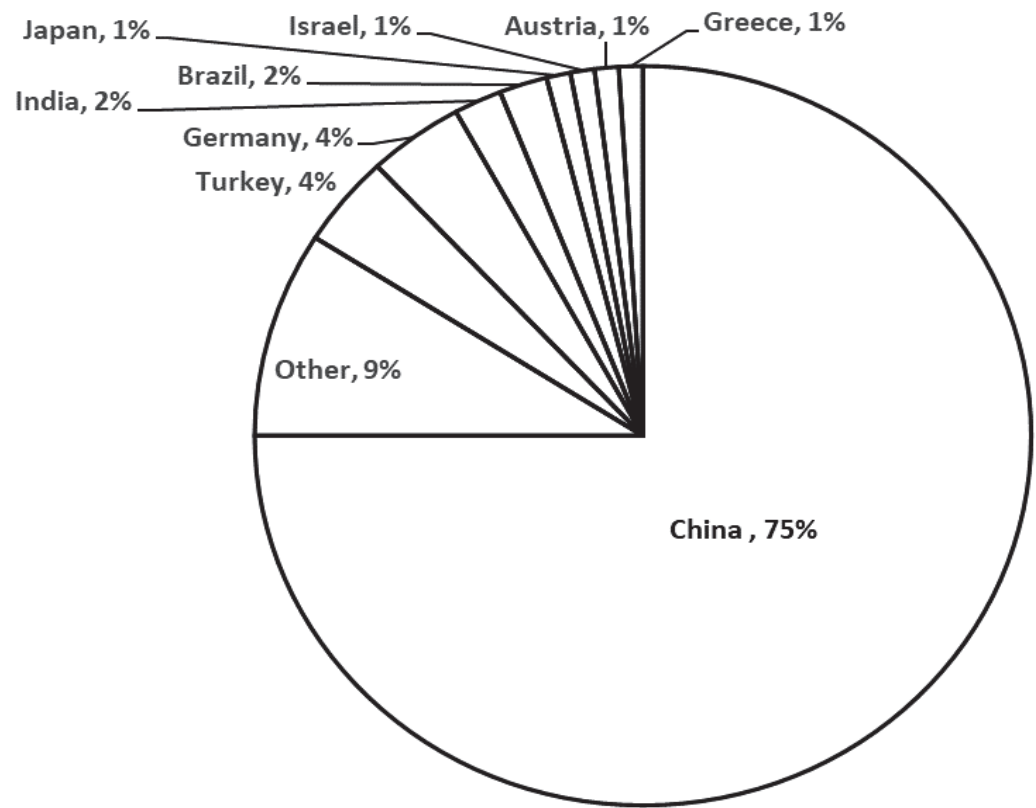

Figure 3: World SWH capacity distribution [4]

The main required characteristics of a solar water heater include:

1. Reasonable initial system cost

2. Minimum use of supplement energy

3. Can tolerate hard water

4. Can avoid freezing and overheating problems

5. High thermal performance

6. Low maintenance requirement

7. Easy to operate

8. Good resistance to hail 
9. Safety

10. Long life

A good SWH system design must adequately satisfy most of the above listed characteristics. It is important to remember that the weight of these requirements can be influenced by climate, location, budget, water quality, system size and house design. In Saudi Arabia there are some additional challenges that may face SWH, which may not exist in other countries. These include:

- Hard water exceeding 400 ppm

- Hail size more than $25 \mathrm{~mm}$ in diameter is common

- Dust accumulation on the collectors

- Large family size comparing to other countries

- Different plumbing design

- Low energy prices

\section{SWH configuration and design optimization}

It is possible to assemble SWHs with several different arrangements. The objective is to come up with the optimum arrangement that has the highest weight in addressing the described ten design requirements. To perform this objective, a weighted score technique was used for selecting the type of collector, circulation, heat exchanging method and hot water storage arrangement. The outcome of the weighted score is the optimum system design configuration, which consists of:

1. Collector type: Flat plate

2. Circulation: Forced circulation

3. Heat exchange: Direct between the tank and collector with a coil inside the tank for customer hot water preheating

4. Storage tank: Split from the collector

Figure 4 shows the proposed optimum SWH arrangement, which is expected to be the best configuration for Saudi Arabia residential sectors or similar environment. The use of unpressurized tank design will help to reduce the cost of the forced circulation system and make it simpler by avoiding the expansion tank and relief valve.

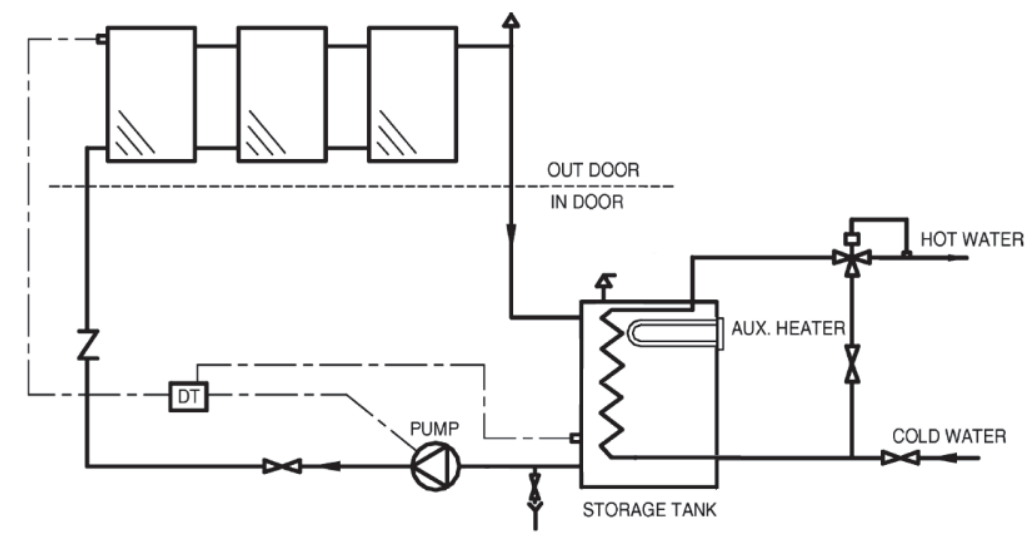

Figure 4: Proposed optimum SWH configuration for residential sector

\section{Simulation methodology}

The collector, circulation, heat exchanger and storage tank designs that meet the desired operation requirements were selected as discussed in section 5 and shown in figure 4 . In addition, it is essential to carefully define and size the system variable parameters, to achieve the highest possible performance during the required time of the year. Table 2 shows the SWH main variable parameters and their investigated range.

The effect of each independent variable parameter on the thermal performance of the SWH system will be evaluated individually. Correlated or linked parameters will be investigated jointly. 
Table 2: SWH variable parameters range

\begin{tabular}{cc}
\hline Factor & Range \\
\hline Collector tilt angle $(\beta)$ & $0-90^{\circ}$ \\
Albedo ratio (Reflection) & $0 ; 0.4 ; 0.8$ \\
Azimuth angle $(\gamma)$ & $90-270^{\circ}$ \\
Collector flow rate & 0.01 to $1 \mathrm{~kg} / \mathrm{s} / \mathrm{m}^{2}$ \\
Tank size & 0.1 to $1 \mathrm{~m}^{3}$ \\
Heat exchanger effectiveness $(\epsilon)$ & 0.2 to 1 \\
Customer supply temperature & 35 to $65^{\circ}$
\end{tabular}

In addition to the effect of above listed system variable parameters in table 2 on the thermal performance of the system; the effect of location is also studied. Five cities in Saudi Arabia with different climatic conditions and population were selected. These cities are Riyadh, Dhahran, Tabuk, Taif and Abha.

The simulation is performed using the recent (Feb/2020) version of System Advisor Model (SAM) by NREL [22] and reliable weather data for the five selected cities obtained from KACARE.

The simulation focus was on maximizing SWH output during the winter season months, which are November, December, January, and February were daily average temperatures are normally below $20^{\circ} \mathrm{C}$. The purpose of selecting the winter months is to maximize the energy delivered during the months where there is a higher demand for hot water. It must be noted that this will result in a reduced annual delivered energy. The selected SWH system inputs for the simulation software are shown in Table 3.

Table 3: Input parameters for simulation

\begin{tabular}{cc}
\hline Factor & Value \\
\hline Daily water demand & $400 \mathrm{l} / \mathrm{day}$ \\
Collector area & $4 \mathrm{~m}^{2}$ \\
FR $\tau \alpha$ & 0.65 \\
$\mathrm{~F}_{\mathrm{R}} \mathrm{U}_{\mathrm{L}}$ & $4.4 \mathrm{~W} / \mathrm{m}^{2} .^{\circ} \mathrm{C}$ \\
incident angle modifier & 0.2 \\
Tank size & $0.5 \mathrm{~m}^{3}$ \\
Tank heat loss & $0.2 \mathrm{~W} / \mathrm{m}^{2} .{ }^{\circ} \mathrm{C}$, \\
Piping length between collectors and tank & $8 \mathrm{~m}$ \\
Pipe insulation conductivity & $0.025 \mathrm{~W} / \mathrm{m} . \mathrm{K}$ \\
Pipe insulation thickness & $2 \mathrm{~cm}$ \\
Utility water inlet temperature & Algorithm linked to ambient
\end{tabular}

Unlike with electric water heaters, the daily hot water consumption profile is critical for proper SWH operation and economics. The estimated 400 litres of daily hot water per household consumption distribution weight pattern is shown in table 4.

Table 4: The estimated daily hot water consumption profile

$\begin{array}{lllllllllllllllllllllllll}\text { Hour } & 1 & 2 & 3 & 4 & 5 & 6 & 7 & 8 & 9 & 10 & 11 & 12 & 13 & 14 & 15 & 16 & 17 & 18 & 19 & 20 & 21 & 22 & 23 & 24 \\ \text { Weight } & 0 & 0 & 0 & 0 & 0 & 3 & 1 & 1 & 1 & 2 & 1 & 1 & 1 & 1 & 1 & 3 & 1 & 1 & 1 & 1 & 3 & 1 & 0 & 0\end{array}$

The software solar water heater energy balance calculations are based on the solar energy equations presented by Duffie and Beckman [23]. Figure 5 shows the essential parameters in evaluating the flat plate collector thermal performance. 




Figure 5: Simplified forced SWH system.

In a flat plate collector, there are optical losses and thermal losses. Optical losses (FR $\tau \alpha)$ represent the losses due to reflection from the top cover glass and not having an ideal absorption from the absorption plate. Thermal loses result from convection and radiation heat transfer to the ambient $\left(F_{R} U_{L}\right)$.

If $\mathrm{G}$ is the incident radiation falling on the collector, and $\mathrm{A}$ is the area of the collector, then the amount of solar radiation falling the collector $\mathrm{Q}_{\mathrm{i}}$ is

$$
Q_{i}=G * A
$$

Part of this energy is being lost due to optical losses, and then $\mathrm{Q}_{\mathrm{i}}$ is being reduced to:

$$
Q_{i}=G *(\tau \alpha) * A
$$

The temperature of the absorber plate will start to increase due to the absorption of the incident solar radiation, and this will create a heat loss $Q_{0}$, which is in relation with the temperature difference between the absorber plate and ambient temperature and the overall collector heat transfer coefficient $\left(\mathrm{U}_{\mathrm{L}}\right)$. $\mathrm{Q}_{\mathrm{o}}$ can be found as

$$
Q_{o}=U_{L} * A *\left(T_{c}-T_{a}\right)
$$

The useful energy absorbed by the solar collector $\mathrm{Q}_{\mathrm{u}}$ is the difference between $\mathrm{Q}$ and $\mathrm{Q}_{\mathrm{o}}$

$$
\mathrm{Q}_{u}=G *(\tau \alpha) * A-U_{L} * A *\left(T_{c}-T_{a}\right)
$$

It is also known that heat gained by a fluid in heat exchanger $\mathrm{Q}_{\mathrm{u}}$ and can be expressed as:

$$
\mathrm{Qu}=\dot{m} * C_{P} *\left(T_{o}-T_{i}\right)
$$

Equation (4) includes collector average temperature, which can be difficult to estimate as it is sometimes different than the average temperature between inlet and outlet. For this reason, the collector heat removal factor $\left(F_{R}\right)$ is used, and it is defined as the ratio between the actual useful energy of the collector to the useful heat gain, if the whole area of the collector at the inlet temperature:

$$
F_{R}=\frac{\dot{m} * C_{P} *\left(T_{o}-T_{i}\right)}{A\left[G * \tau \alpha-U_{L} * A *\left(T_{i}-T_{a}\right)\right]}
$$

The useful energy $\mathrm{Q}_{\mathrm{u}}$ can be then be written as:

$$
\mathrm{Qu}=F_{R} * A\left[G * \tau \alpha-U_{L} * A *\left(T_{i}-T_{a}\right)\right]
$$

Equation (7) is an especially important relation and generally known as the Hottel-Whillier-Bliss equation. If we want to measure the thermal collector efficiency over time, then:

$$
\eta=\frac{\int Q_{i} d t}{A \int G d t}
$$

SAM software will run hourly and make heat balance across the SWH storage tank. If the temperature is not high enough, it will consider that electric heater will provide the heat and calculate what is called auxiliary energy. Finally, the software will be able to provide any energy information such solar fraction, energy saved, etc. Also, the software will be able to provide main economic figures, such payback period, NPV. and IRR if 
required.

\section{Results and discussion}

The effect of six key thermal and economical parameters of SWH systems on the overall system performance has been studied at five different climatic locations in Saudi Arabia. These parameters include:

- System energy $(\mathrm{kWh})$ : Electric energy avoided by using SWH systems instead of electrical water heating systems. This energy will be used for economic analysis.

- Delivered energy (kWh): Thermal energy delivered by the SWH system to the solar insulated storage tank.

- Auxiliary heat $(\mathrm{kWh})$ : Electric power consumed by the auxiliary heater to increase the water temperature from the solar storage tank to the required pre-set temperature.

- Auxiliary heat only $(\mathrm{kWh})$ : Electric power that would be required when using electrical water heating system only and no solar energy is used.

- Solar fraction (\%): The ratio of benefited solar energy to the total energy delivered to the water storage tank to achieve the set temperature.

- $\quad$ Payback period (Years): is the duration in years that it takes for annual savings to equal the annual costs.

The effect of each independent or correlated variables on the above parameters have been studied and the results are discussed and presented graphically.

The first results pertain to the effect of collector tilt angle $(\beta)$ and albedo ratio on the thermal performance of the SWH system was simulated. These two variables are correlated with each other. Higher albedo ratio will boost the solar delivered energy from collectors with tilt angle higher than $50^{\circ}$. This is because low $\beta$ collectors will not benefit from reflected solar radiation. Figure 6 shows the effects of changing the collector tilt angle and albedo ratio for Riyadh city. Similar trends were obtained for the other four cities studies. Also, it can be observed from the same figure that small deviation from optimum tilt angle will not cause a major reduction in the delivered energy. Adjusting the collector to an angle of $50^{\circ}$ will ensure optimum performance in winter and lower overheating problems in summer.

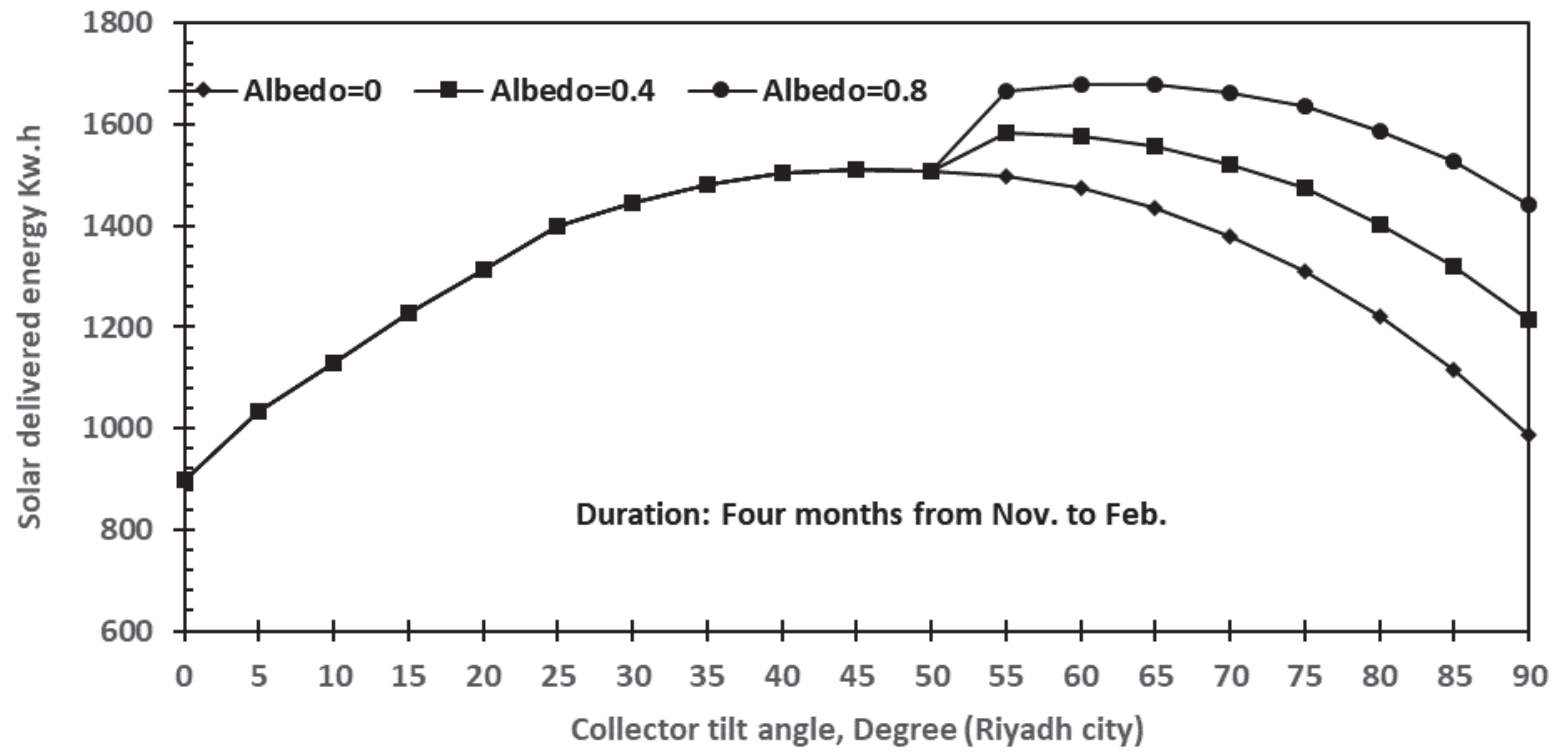

Figure 6: Riyadh city data for collector tilt angle and albedo effect

Presently, roofs utilizing high reflection coating are highly recommended to reduce the summer residential building heat gain. At the same time, this coating can play an important role in increasing the delivered energy for collectors with high tilt angle. Also, it should be noted that a high tilt angle will provide the lowest energy during summer months, which is an advantage to avoid common overheating problems.

The second results pertain to the effect of collector azimuth angle on the thermal performance of the system. Collector azimuth angle $(\gamma)$ is defined as the collector orientation angle in reference to the south direction. If the collector is facing True South, then its azimuth is $0^{\circ}$ or sometimes $180^{\circ}$ if convention is to start from north. Figure 7 shows the effects of changing the azimuth angle on the solar collectors delivered energy for the five selected cities. Moving the collector orientation away from optimum angle will reduce the delivered energy and at $90^{\circ}$ away from optimum orientation, the delivered energy will be reduced by $50 \%$. 


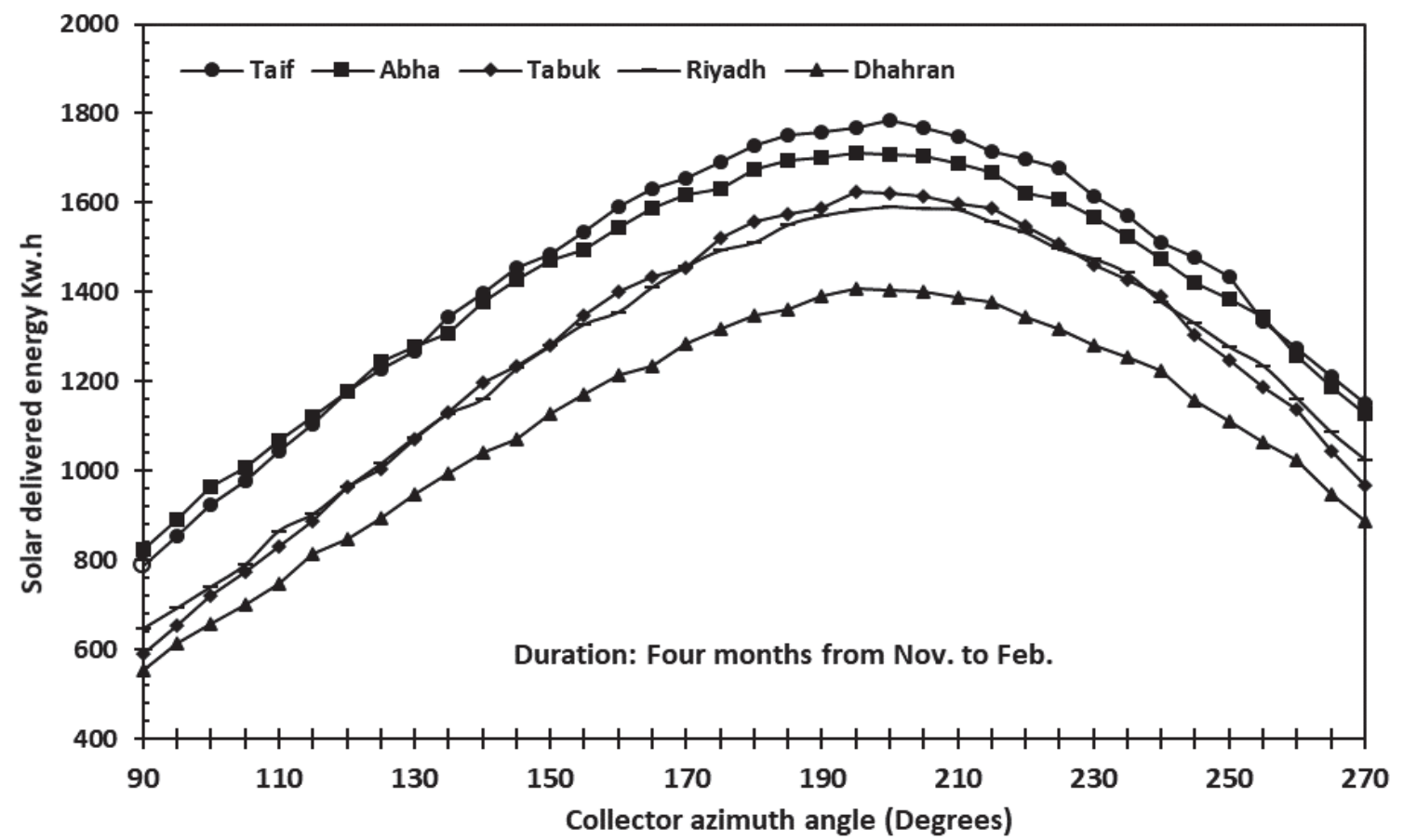

Figure 7: Azimuth angle effect on winter delivered energy for five cities

Theoretically, if we are in the northern hemisphere then directing the collector to the true south will provide the collector with the maximum gain. As shown in the figure 7 , we can get an extra $4 \%$ more energy by directing the collector $20^{\circ}$ further to the west direction or at angle of $200^{\circ}$. This interesting observation can be explained due to the fact that solar radiation for the second half of the day is normally more intense than the first part of the day, which has been verified by the values of ground station hourly data. At the same time losses at the second half of the day is lower than the first half. Also, it can be noticed that only a significant deviation from the optimum azimuth angle can cause a sharp drop in produced energy. The value of $\beta$ used in the simulation for each city is the optimum angle obtained at Albedo $=0$.

The third results pertain to the effect of flow rate and heat exchanger effectiveness on the thermal performance of the SWH system. These two variables are correlated with each other. As we can see from figure 8 , the lower heat exchanger effectiveness $(\epsilon)$ will require more recirculation flow rate to maintain the same delivered energy. When $\epsilon$ is high, the SWH system will provide more energy at reduced flow rate. This is due to the stratification effect in the storage tank, which will promote lower inlet temperature to the collectors. From a practical aspect, maintaining a stratified tank is not an easy task, and as a result it is always recommended to keep the recirculation rate at least $0.015 \mathrm{~kg} / \mathrm{s} / \mathrm{m}^{2}$.

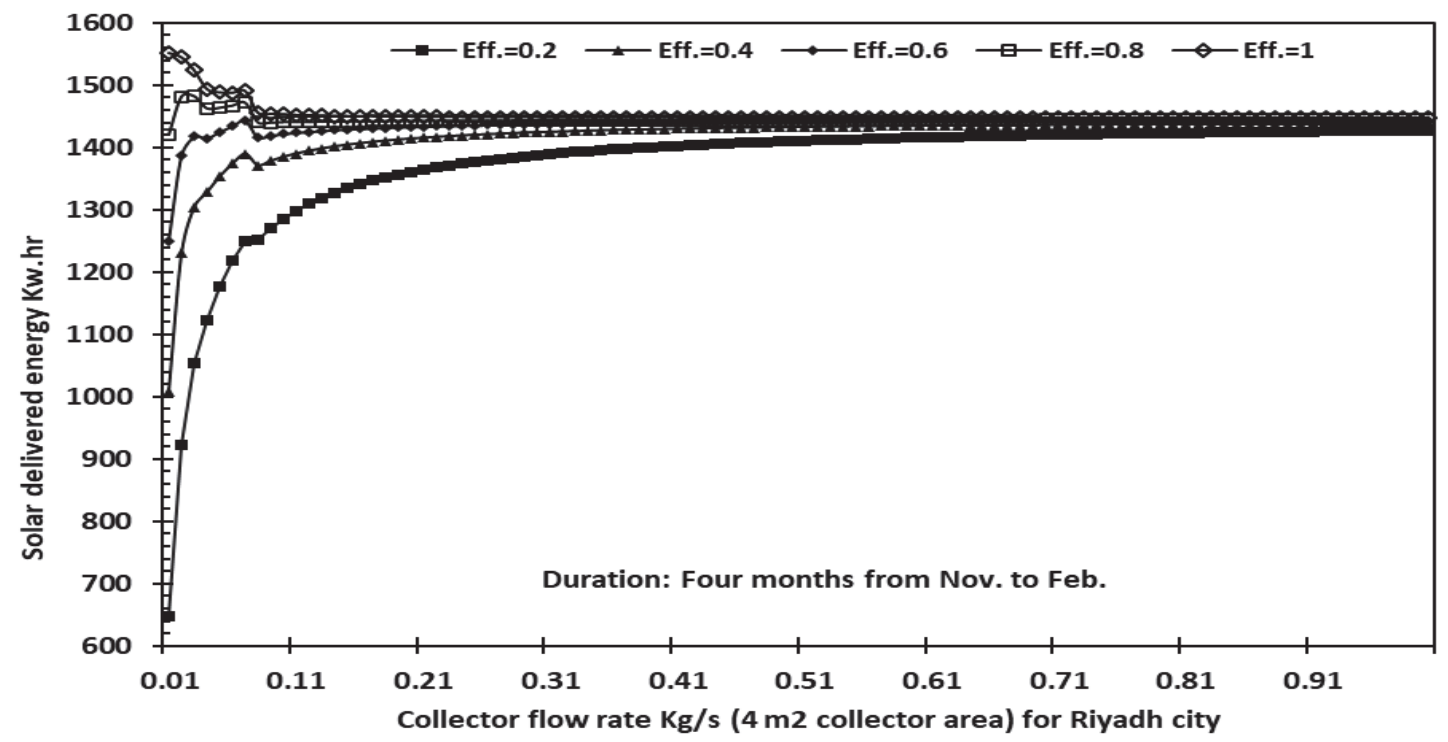

Figure 8: Collector flow rate and heat exchanger effectiveness 
The fourth results pertain to the effect of tank size on the thermal performance of the system. An undersized tank will increase the use of auxiliary electrical energy and reduce solar fraction, while oversized tank will significantly increase the system capital cost and therefor affect the economics of the SWH system. Figure 9 shows the effect of tank size on $400 \mathrm{~L} /$ day hot water demand with the consumption profile shown in table 4 . The increase of tank size reduces the auxiliary electrical energy sharply until reaching a tank size of $0.3 \mathrm{~m}^{3}$, where any further increase will result in a minor reduction in auxiliary electrical energy. In practice, it is recommended to increase the tank size to $0.5 \mathrm{~m}^{3}$ to overcome any possible deviation from the estimated hot water consumption profile and minimize energy waste. The simulations were carried out using the optimum $\beta$ and $\gamma$ for each city. The two cities requiring more auxiliary energy are the ones with lower ambient temperatures in winter.

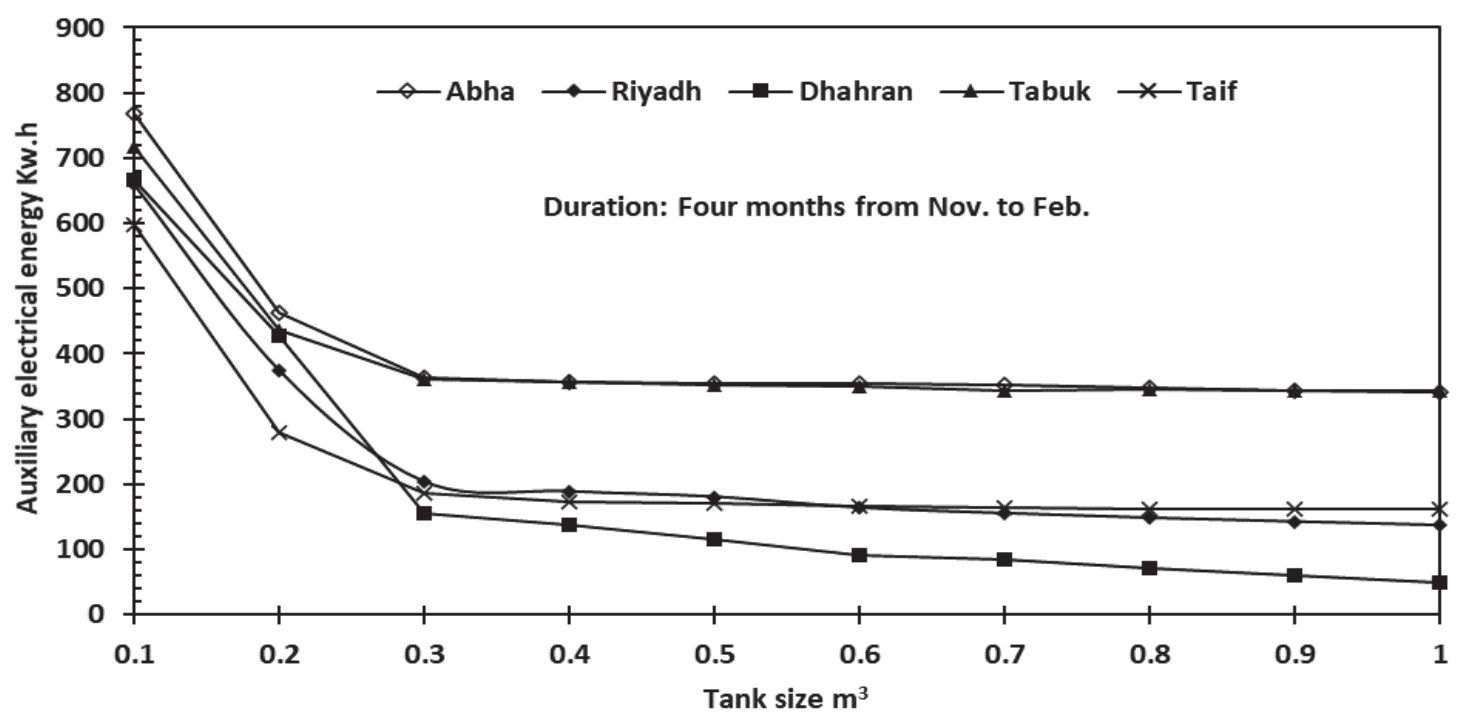

Figure 9: Tank size effect on auxiliary electrical energy (Riyadh city)

The fifth results pertain to the effect of customer supply temperature on the thermal performance of the system. The majority of SWH installations are normally equipped with supplementary electrical heaters that boost the customer supply temperature in case the solar storage tank temperature is below the customer temperature set-point. The set-point temperature is extremely critical and can significantly increase the energy requirement of both traditional electrical heating system as well as SWH system. The energy requirement can be exacerbated in houses equipped with a central hot water circulation system. Such systems consist of long pipes with little or no thermal insulation resulting in heat leakages. Figure 10 shows the effect of increasing the customer supply on the required auxiliary electrical energy, where auxiliary energy sharply increases after the preferred temperature of $45^{\circ} \mathrm{C}$. The effect is worse at locations with lower ambient temperatures.

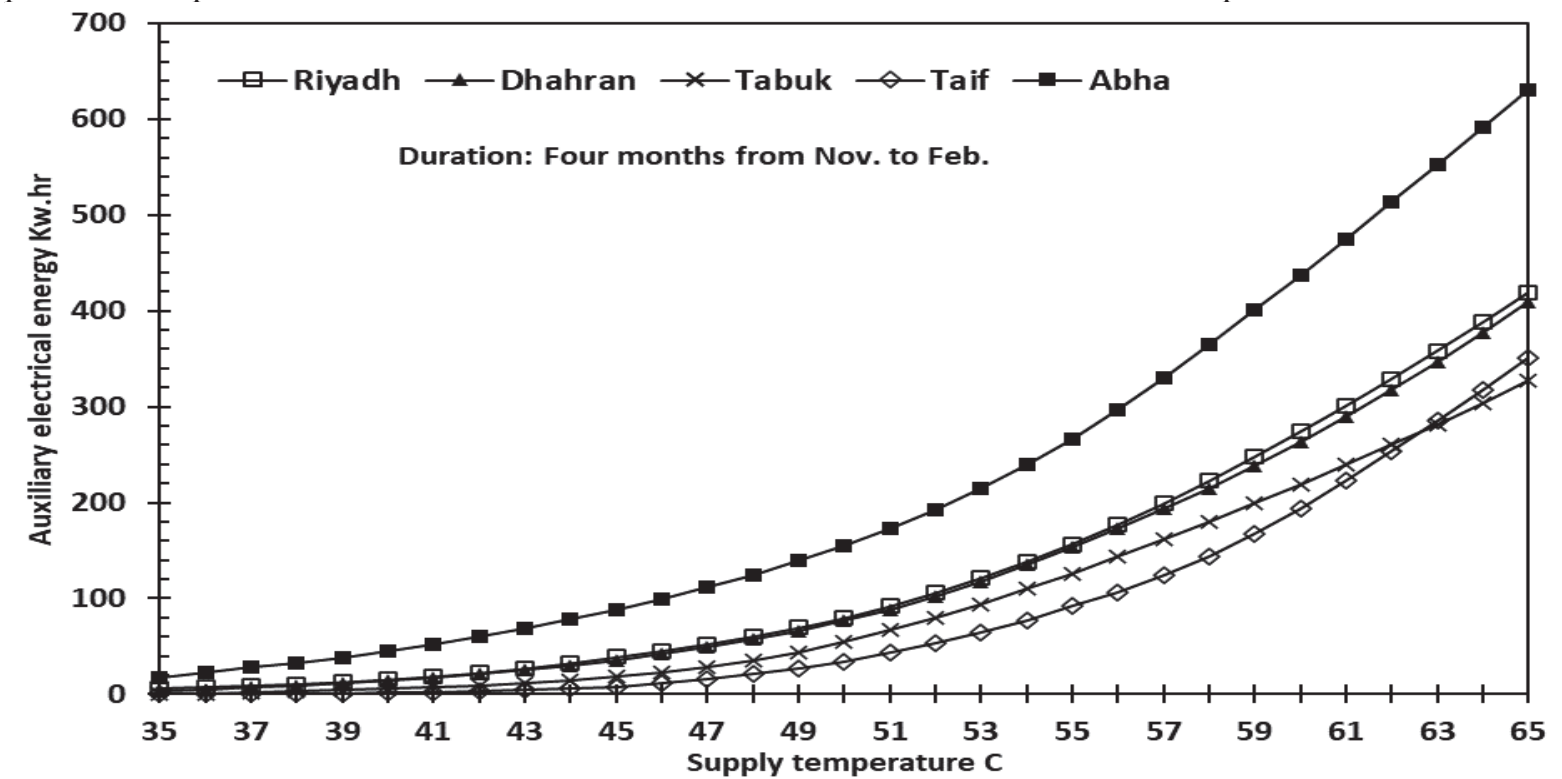

Figure 10: Customer supply temperature effect on auxiliary electrical energy 


\section{Economic, energy and environmental benefit analysis}

One of the main incentives of installing a SWH system in Saudi Arabia is to reduce the electricity bill. No other incentive schemes, such as carbon credits, are available to date. The yearly energy quantities as well as the payback periods of installing residential SWH systems in five cities with different climatic conditions are shown in Table 5.

Table 5: Yearly energy quantities and payback periods

\begin{tabular}{cccccc}
\hline Item & Riyadh & Dhahran & Tabuk & Taif & Abha \\
\hline System energy $(\mathrm{kWh})$ & 3207 & 2944 & 3370 & 3304 & 3589 \\
Q delivered $(\mathrm{kWh})$ & 5312 & 5347 & 5632 & 5549 & 6345 \\
Q auxiliary only $(\mathrm{kWh})$ & 4670 & 4036 & 4856 & 4670 & 5594 \\
Q auxiliary $(\mathrm{kWh})$ & 427 & 236 & 324 & 274 & 601 \\
Solar fraction $(\%)$ & 0.69 & 0.73 & 0.69 & 0.71 & 0.64 \\
Payback period (years) & 4.39 & 4.76 & 4.19 & 4.27 & 3.95
\end{tabular}

The data shown in table 5 indicates that:

a. Residential SWH systems are currently economically feasible with a payback period ranging from 4 to 4.8 years.

b. Abha city has the lowest payback period (around 4 years) due to high demand for hot water as a result of having a lower annual average ambient temperature.

c. Tabuk city has also low payback period (around 4 years) due high incident solar radiation resulted from clear skies.

d. Two collectors with total area of $4 \mathrm{~m}^{2}$ were found to be the most economical option. Improving the solar fraction (by having more collectors) will increase the payback period.

e. It is possible to significantly reduce the auxiliary energy and increase the solar fraction by relaxing the customer hot water supply temperature requirement to below $45^{\circ} \mathrm{C}$.

f. Among five selected cities, Dhahran has the lowest hot water demand, which results in a longer payback period.

g. Payback period has an inverse relation with solar fraction. Lower solar fraction indicates a higher demand for hot water. This is because more capital cost will be utilized for short time during the year.

In the year 2019 the residential sector in Saudi Arabia consumed about 128 TW-hr of electricity [24] . Considering that the hot water energy demand is about $15 \%$ of the overall residential electricity demand, the potential annual electricity saving by wide implementation of SWH in Saudi Arabia would be around 19.2 TW$\mathrm{hr}$. Assuming an average electrical power generation and transmission efficiency of 30\%; 36.2 million barrels of fossil fuel/year can be saved by wide use of residential SHW systems in the KSA. Such saving in fossil fuel will result in an annual reduction of 15.3 million tons of carbon dioxide emissions. The saved energy and avoided carbon dioxide emissions is equivalent to shutting down a thermal power plant with a capacity of $2.1 \mathrm{GW}$.

\section{Commercial and industrial applications}

Even though this study is focusing on the technical and economic feasibility of using residential SWH systems; the potential use of SWH systems in commercial and industrial sectors will have a better economic feasibility due to high utilization rate of hot water around the year.

\section{Conclusions}

The implementation of SWH in Saudi Arabia for residential, commercial and industrial sectors is very low compared to other Middle East countries as well as world average implementation rate. The low energy prices as well as lack of awareness and incentives are the main reasons for low utilization of SWH. The current study conclusions include:

- Saudi Arabia has high solar radiations resources across the year due to its location and weather condition. Some locations receive more beam radiation, e.g., Tabuk due to clear skies, while other places like Dhahran has high diffuse radiation due to high humidity and dust concentrations.

- The retrofitting of SWH in old residential buildings is economical and the existing electrical heater storage tank can be reused as a solar storage tank, which will significantly reduce the system cost.

- The use of forced circulation system concept considered in this study was found to be the most practical in solving major technical problems associated with thermosyphon SWH design, including overheating, freezing, overpressure, scaling and space requirement. A proper SWH system design must address the high impact factors that affect SWH system performance, which may differ from one location to another.

- Optimizing the collector tilt and azimuth angles were noticed to increase solar delivered energy during the winter at no additional cost. In all locations, the optimum azimuth was found to be $20^{\circ}$ away from the 
traditional $180^{\circ}$ south oriented collector. This is due to higher beam radiation during the second half of the day.

- The new building practice of having a centralized hot water heater on the roof with a recirculation network will significantly increase the hot water demand, especially if the piping network is long and not well thermally insulated.

- The solar water tank needs to be sized probably to meet night demand and to overcome hot water requirement fluctuation.

- The recommended collector circulation rate is $0.015 \mathrm{~kg} / \mathrm{s} / \mathrm{m}^{2}$. More recirculation is required is if a small heat exchanger with low effectiveness is utilized.

- A wide utilization of SWH in the residential sector can result to a significant saving in energy and supports the efforts for $\mathrm{CO}_{2}$ abatement.

- Similar to residential sector, there is also a high potential of economical use of SWH in commercial, government and industrial sectors.

- There was a noticeable difference between the weather data measured by ground stations compared to those provided by satellite measurement. It is highly recommended to use ground collected data whenever it is available and reliable.

\section{Acknowledgment}

The author acknowledge the support of King Fahd University of Petroleum Minerals (KFUPM), in carrying out this study and King Abdullah City for Atomic and Renewable Energy (KA-CARE) for providing weather data.

\section{References:}

[1] “Renewables 2019 Global Status Report,” 2019. doi: 10.3390/resources8030139.

[2] Marimuthu C and Kirubakaran V, "Carbon Payback Period and Energy Payback Period for Solar Water Heater,” Int. Res. J. Environ. Sci. Int. Sci. Congr. Assoc., vol. 3, no. 2, pp. 93-98, 2014, [Online]. Available: www.isca.me.

[3] ECRA, "ECRA Electricity data," 2019. https://www.ecra.gov.sa/.

[4] IRENA, "Solar Heating and Cooling for Residential Applications," Iea; Etsap; Irena, no. January, pp. 1-40, 2015, [Online]. Available: https://www.irena.org//media/Files/IRENA/Agency/Publication/2015/IRENA_ETSAP_Tech_Brief_R12_Solar_Thermal_Resi dential_2015.pdf.

[5] E. Zell et al., "Assessment of solar radiation resources in Saudi Arabia," Solar Energy, vol. 119. pp. 422-438, 2015, doi: 10.1016/j.solener.2015.06.031.

[6] "https://solargis.com/maps-and-gis-data/overview," 2019. .

[7] Hamad Almahmoud; Fahad A. Al-Sulaiman;Hafiz Abd-ur-rehman, "Techno-Economic Evaluation Of Solar Water Heating Applications At Hospitals In Saudi Arabia,” ISES, no. November, pp. 8-12, 2015.

[8] V. Santos and T. Giglio, "An approach to investigate the interface between built environment and thermosyphon solar water heating system," Energy and Buildings, vol. 223. 2020, doi: 10.1016/j.enbuild.2020.110092.

[9] T. Kitzberger, D. Kilian, J. Kotik, and T. Pröll, "Comprehensive analysis of the performance and intrinsic energy losses of centralized Domestic Hot Water (DHW)systems in commercial (educational)buildings," Energy and Buildings, vol. 195. pp. 126-138, 2019, doi: 10.1016/j.enbuild.2019.05.016.

[10] P. Feliński and R. Sekret, "Effect of PCM application inside an evacuated tube collector on the thermal performance of a domestic hot water system," Energy and Buildings, vol. 152. pp. 558-567, 2017, doi: 10.1016/j.enbuild.2017.07.065.

[11] J. Deng, S. Furbo, W. Kong, and J. Fan, "Thermal performance assessment and improvement of a solar domestic hot water tank with PCM in the mantle," Energy and Buildings, vol. 172. pp. 10-21, 2018, doi: 10.1016/j.enbuild.2018.04.058.

[12] W. T. Li, W. Tushar, C. Yuen, B. K. K. Ng, S. Tai, and K. T. Chew, "Energy efficiency improvement of solar water heating systems - An IoT based commissioning methodology," Energy and Buildings, vol. 224. 2020, doi: 10.1016/j.enbuild.2020.110231.

[13] T. Giglio and R. Lamberts, "Savings related to solar water heating system: A case study of low-income families in Brazil," Energy and Buildings, vol. 130. pp. 434-442, 2016, doi: 10.1016/j.enbuild.2016.08.076.

[14] H. M. Abd-Ur-Rehman and F. A. Al-Sulaiman, "Optimum selection of solar water heating (SWH) systems based on their comparative techno-economic feasibility study for the domestic sector of Saudi Arabia," Renew. Sustain. Energy Rev., vol. 62, pp. 336-349, 2016, doi: 10.1016/j.rser.2016.04.047.

[15] S. H. Farjana, N. Huda, M. A. P. Mahmud, and R. Saidur, "Solar process heat in industrial systems - A 
global review," Renewable and Sustainable Energy Reviews, vol. 82. pp. 2270-2286, 2018, doi: 10.1016/j.rser.2017.08.065.

[16] A. Endale, "Analysis of status, potential and economic significance of solar water heating system in Ethiopia," Renewable Energy, vol. 132. pp. 1167-1176, 2019, doi: 10.1016/j.renene.2018.08.094.

[17] T. A. Yassen, N. D. Mokhlif, and M. A. Eleiwi, "Performance investigation of an integrated solar water heater with corrugated absorber surface for domestic use," Renewable Energy, vol. 138. pp. 852-860, 2019, doi: 10.1016/j.renene.2019.01.114.

[18] E. Vengadesan and R. Senthil, "A review on recent development of thermal performance enhancement methods of flat plate solar water heater," Solar Energy, vol. 206. pp. 935-961, 2020, doi: 10.1016/j.solener.2020.06.059.

[19] L. Salgado-Conrado and A. Lopez-Montelongo, "Barriers and solutions of solar water heaters in Mexican household," Solar Energy, vol. 188. pp. 831-838, 2019, doi: 10.1016/j.solener.2019.06.021.

[20] T. Urmee, E. Walker, P. A. Bahri, G. Baverstock, S. Rezvani, and W. Saman, "Solar water heaters uptake in Australia - Issues and barriers," Sustainable Energy Technologies and Assessments, vol. 30. pp. 11-23, 2018, doi: 10.1016/j.seta.2018.08.006.

[21] KACARE, "King Abdullah City for Atomic and Renewable Energy Weather Data." https://rratlas.energy.gov.sa/RRMMPublicPortal/.

[22] NREL, "System Advisor Model (SAM)." https://sam.nrel.gov/download.html.

[23] J. A. Duffi and W. A. Beckman, Solar Engineering of Thermal Processes. 2013.

[24] "Saudi Arabia Monetary Agency Annual Report," 2019. [Online]. Available: http://www.sama.gov.sa/en-US/EconomicReports/Pages/AnnualReport.aspx. 